\title{
Ritual de consumo do crack: aspectos socioantropológicos e repercussões para a saúde dos usuários
}

\author{
The ritual of crack consumption: \\ socio-anthropological aspects and impacts on the health of users
}

Maria Salete Bessa Jorge ${ }^{1}$

Paulo Henrique Dias Quinderé ${ }^{1}$

Silvio Yasui ${ }^{2}$

Renata Alves Albuquerque ${ }^{1}$

${ }^{1}$ Saúde Pública,

Universidade Estadual do

Ceará. Av. Paranjana, 1700, Itaperi.

60740-000 Fortaleza CE. maria.salete.jorge@gmail.com

${ }^{2}$ Departamento de psiquiatria, Faculdade de Medicina, Universidade Estadual Paulista Júlio de Mesquita Filho.

\begin{abstract}
The use of crack cocaine has given rise to an intense discussion in society. Research has contributed to the characterization of users and the negative consequences of its use. However, few studies have conducted in-depth study of the social and cultural contexts in which crack cocaine is used. Thus, this study seeks to discuss the ritual of crack cocaine use and its social and health consequences for the user. It is a qualitative study developed in the Psychosocial Care Centers for Alcohol and Drugs (Portuguese acronym: Caps-ad). The individuals were selected in two groups of keyinformants: crack cocaine users undergoing treatment and health professionals. Data was obtained by means of semi-structured interviews. The results revealed that the use of crack cocaine is not dissociated with the current organizational structure of society. There is a link between the use of this substance and the social organization for its use. By using crack cocaine, the individuals try to be part of a consumer market, actively participating in what society perceives as new. The forms and locations of use are directly related to users' health, making it necessary for healthcare services to detect, approach and make health interventions in these locations of use.
\end{abstract}

Key words Crack cocaine, Substance-related disorders, Social and anthropological aspects, Detriments to health
Resumo O uso do crack tem promovido intensa discussão na sociedade. Pesquisas têm contribuído na caracterização dos usuários e nas consequências negativas do seu consumo. No entanto, poucos estudos têm se aprofundado nos contextos socioculturais em que o crack é consumido. Para tanto, o estudo tem como objetivo discutir o ritual de consumo do crack e suas repercurssões sociais e à saúde dos usuários. Trata-se de um estudo qualitativo desenvolvido nos Centros de Atenção Psicossocial Álcool e Drogas (Caps-ad). Os sujeitos foram selecidonados em dois grupos de informantes-chave: usuários de crack em acompanhamento e trabalhadores de saúde. Utilizou-se como técnica de coleta a entrevista semiestruturada. Os resultados demonstraram que o consumo de crack não está dissociado do modo de organização atual da sociedade. Há relação entre o uso desta substância e a organização social para o consumo. Os indivíduos buscam no crack fazer parte de um mercado consumidor, participando ativamente do que a sociedade concebe como novidade. As formas e as cenas de uso têm relação direta com a saúde dos usuários, necessitando que haja por parte dos serviços de saúde detecção, aproximação e intervenções de saúde nessas cenas de uso.

Palavras-chave Cocaína-crack, Transtornos relacionados ao uso de substâncias, Aspectos socioantropológicos, Agravos à saúde 


\section{Introdução}

O uso do crack difundiu-se nas áreas pobres dos centros urbanos das cidades de Los Angeles, Miami e Nova York, nos Estados Unidos, nos anos de 1984 e 1985. Era obtido a partir de um processo caseiro e utilizado em grupos, em espaços abandonados e precários. Em geral os usuários eram na sua maioria, jovens, usuários de cocaína, atraídos pelo seu preço baixo'.

No Brasil, o consumo do crack, aparece em bairro da Zona Leste de São Paulo, espalhandose posteriormente para as áreas centrais da Capital paulista. O primeiro estudo realizado em 1989 sobre o consumo de crack, também mostrou que o perfil dos usuários era de homens, menores de 30 anos, desempregados, com baixa escolaridade e poder aquisitivo ${ }^{2}$. Os dados do I e do II Levantamento Epidemiológico demonstram uma maior prevalência do uso de cocaína e crack pelos homens. Em 2001 a maior porcentagem de uso na vida foi para o sexo masculino $(1,2 \%)$, na faixa etária de 25 a 34 anos (0,7\%), e em 2004 observa-se que entre os brasileiros das 108 cidades pesquisadas a maior porcentagem de uso na vida foi para o sexo masculino $(3,2 \%)$, na faixa etária de 25 a 34 anos $^{3,4}$.

Dados do II Levantamento Nacional sobre o consumo de cocaína e crack, mostram que aproximadamente 2 milhões de pessoas fizeram uso da cocaína na sua forma fumada (Crack/Merla, Oxi), representando $1,4 \%$ dos adultos e $1 \%$ dos jovens.

A produção científica acerca do consumo de crack tem se intensificado a partir das décadas de 1980 e 1990, quando há as primeiras aparições do uso desta substância. Os estudos ${ }^{1-4}$ têm procurado demonstrar as formas de uso, o perfil dos usuários e as péssimas condições sociais às quais os estes estão submetidos, traçando uma estreita relação entre o uso desta substância e as deletérias consequências do seu consumo.

Os perfis de usuário, geralmente encontrados, são de homens, com baixa escolaridade e, em sua grande maioria, desempregados ou sem vínculo formal com trabalho ${ }^{6-8}$. Este aspecto chama a atenção para o fato de que a substância psicoativa, o crack, pode ter uma inserção maior nessas populações com maior vulnerabilidade social.

Embora, tenha-se avançado na caracterização dos usuários, pouco se tem pesquisado acerca dos aspectos culturais e socias em que se constitui este fenômeno do uso do crack. A contextualização do entorno sociocultural, bem como a experiência dos efeitos das substâncias psicoati- vas são relevantes para se construir novas formas de abordagem aos usuários. Compreendendo como os estes experimentam os efeitos e como ocorrem os rituais de consumo no contexto do grupo social, se consegue ampliar o conhecimento e o escopo de intervenções da saúde sobre esses grupos.

Existe pouca discussão acerca dos aspectos sociais e culturais envolvidos no fenômeno do consumo. São negligenciados aspectos relacionados às experiências dos usuários e o que estes demandam em relação aos cuidados de saúde. Desta forma, os estudos na área da saúde continuam a valorizar as pesquisas epidemiológicas que geralmente privilegiam as prevalências da dependência química na população, usando instrumentos de diagnósticos com questões fechadas. Essas pesquisas não têm se preocupado com os fatores socioculturais que permeiam o consumo de substâncias psicoativas, e buscam por meio da causalidade positivista biomédica a relação entre o agente patogênico (droga) e o organismo enfermo (usuário de droga). Assim, deixa de considerar todo o contexto em que ocorre o consumo e realizam diagnósticos generalizantes sem nenhum contato com os indivíduos?.

As regras estabelecidas pelo grupo e os controles sociais, sejam eles formais ou informais, são de vital importância para compreender o contexto de uso de uma substância psicoativa. Estes controles funcionam: definindo o que é uso aceitável e condenando os que fogem a esse padrão; limitando o uso a meios físicos e sociais que propiciem experiências positivas e seguras; identificando efeitos potencialmente negativos, ou seja, os padrões de comportamento ditam cuidados a serem tomados antes, durante e depois do uso, e distinguindo os diferentes tipos de uso das substâncias respaldado nas obrigações e relações que os usuários mantêm em esferas não diretamente associadas aos psicoativos ${ }^{10}$.

Os controles sociais informais desenvolvidos pelos usuários ressaltam, também, a influência do cenário social, os quais contribuem e funcionam como uma forma de autocontrole dos consumidores e dos respectivos grupos de referência. Autocontrole ou autorregulação consiste em estratégias individuais e fatores de proteção subjetivos desenvolvidos pelo próprio usuário, a partir de suas próprias experiências, crenças e valores ${ }^{10}$.

Além dos valores e regras de conduta, chamados por Norman Zinberg ${ }^{10}$ de sanções sociais, haveria, também, a observância de rituais sociais de uso, ou seja, padrões de comportamentos estabelecidos nos grupos em relação ao consumo 
da substância psicoativa, tais como métodos de aquisição da droga e formas de uso, seleção do meio físico e social para que ocorra o consumo, atividades empreendidas sob seu efeito e as maneiras de evitar consequências danosas ${ }^{11}$.

Desta forma, pouco tem se levado em consideração os aspectos sociais relacionados a este consumo, quais as estratégias de autocontrole que os usuários utilizam para minimizar os danos sociais e à saúde. Diante disso, o presente estudo tem como objetivo discutir o ritual de consumo do crack e as repercussões sociais, bem como a saúde dos usuários.

\section{Metodologia}

Trata-se de um estudo qualitativo com análise hermenêutica. A proposta do estudo hermenêutico tem a sua importância na compreensão da dimensão simbólica existente nos diversos espaços sociais em que o indivíduo se inscreve, ou seja, do sistema de crenças no entendimento dos processos físicos do corpo. Este fenômeno social, que é o uso de drogas, carece ser compreendido como um fato social total, que afeta a fisiologia, catalisa emoções dos indivíduos e interferem em suas relações comunitárias, construindo uma totalidade social específica.

Como destaca Oriol Romaní12, a utilização dos estudos qualitativos, na área do uso de drogas, possibilita uma compreensão da realidade, que implica uma interação continuada e intensa com o grupo estudado no seu ambiente natural. Permite acessar, de maneira imediata, as informações através do contato direto com os sujeitos envolvidos no contexto microssocial onde estão concentradas as experiências da população estudada.

O estudo foi desenvolvido nos Centros de Atenção Psicossocial Álcool e Drogas (Caps-ad) das Secretarias Executivas Regionais (SER) IV e V do Município de Fortaleza (CE). A escolha pelo território administrativo-político das SER IV e V deve-se ao fato das mesmas estarem pactuadas no Sistema Municipal Saúde-Escola (SMSE) em que a Universidade Estadual do Ceará (UECE) e a Prefeitura de Fortaleza desenvolvem parcerias no âmbito da formação e de atividades sociocomunitárias.

Os participantes da pesquisa foram definidos pela saturação teórico-empírica e pela relevância das informações e das observações que indiquem contribuições significantes e adequadas ao delineamento do objeto em apreensão.
Para conformação dos sujeitos foram selecionados dois grupos de informantes-chave: Grupo I - 21 usuários de crack em acompanhamento nos Caps-ad; Grupo II - 15 trabalhadores dos Capsad (9 Profissionais, 2 psicólogos, 2 Terapeutas ocupacionais, 1 auxiliar de enfermagem, 2 enfermeiros, 1 farmacêutico, 1 assistente social e 6 trabalhadores de nível médio, do apoio administrativo e de serviços gerais).

O contexto em que se insere o presente estudo está engendrado por personagens de classes sociais distintas. Os usuários de crack, em acompanhamento nos Caps-ad, provêm de um contexto socioeconômico precário de bairros com intensas vulnerabilidades sociais. Consiste num grupo formado eminentemente por homens, adultos jovens, com média de 32 anos de idade, escolaridade até o ensino médio, realizando algum tipo de atividade remunerada e estando há pelo menos um mês em acompanhamento no serviço.

Quanto aos trabalhadores de saúde, são, na sua maioria, mulheres, com idade média de 36 anos, com renda de 1 salário mínimo ou mais, com vínculos trabalhistas garantidos e com pelo menos 3 anos de trabalho no serviço.

Utilizou-se como técnica de coleta a entrevista semiestruturada, com questões sobre o inicio do consumo do crack, formas de uso e locais de consumo e as experiência do uso - efeitos e sensações, sentidos e significados do uso.

Todas as entrevistas foram gravadas na íntegra em aparelhos digitais, com autorização prévia dos entrevistados, mediante a realização de leitura e assinatura do termo de consentimento livre e esclarecido. Concluída a gravação, o material foi colocado à disposição dos entrevistados, para ouvir suas respostas e, caso desejasse, poder modificar ou acrescentar questões relativas ao seu depoimento.

$\mathrm{Na}$ análise das narrativas utilizou-se como referência o tema: rituais de consumo e espaços de uso do crack. Embora o uso de psicoativos possa tornar-se uma atividade predominante, raramente ela é uma atividade isolada, e geralmente é social, que envolve a disponibilidade da droga, valores, regras, rituais e estrutura de vida ${ }^{13}$. O tema foi representado por subtemas: início do uso, formas de uso e locais de consumo.

Para Paul Ricoeur ${ }^{14}$ as narrativas são uma operação mediadora entre a experiência viva e o discurso, as quais ligariam a explicação à compreensão, no sentido de buscar no enredo a coerência e a mediação entre ação e linguagem e entre indivíduo e sociedade. O centro da abordagem hermenêutica está na compreensão do tex- 
to, procurando entender a multiplicidade de significados, tentando clarear o que é confuso, escondido e fragmentado. Trata-se de um pensamento que se propõe a adotar um método reflexivo capaz de romper todo e qualquer pacto com o idealismo.

Os conceitos utilizados para a construção do processo analítico dizem respeito ao distanciamento, apropriação, explicação e compreensão das experiências vividas ${ }^{15}$. As etapas de análise foram constituídas de transcrição das entrevistas em texto: distanciamento (distanciação), interpretação superficial (naive), análise estrutural e compreensão abrangente do texto, denominada de interpretação profunda.

A análise das narrativas está pautada na proposição metodológica e analítica fundamentada na hermenêutica. Em detalhe, propõem-se como síntese deste método, os passos descritos para interpretação dos resultados em dois níveis: das determinações fundamentais e do encontro com os fatos empíricos. Segundo previsto, o processo de evidenciação das sínteses foi discutido entre os participantes, implementado a partir de olhares e experiências dos participantes envolvidos e articulado com a literatura disponível na área de conhecimento.

A partir do material construído com as entrevistas dos dois de grupos de informantes-chave, procedeu-se a aproximação com o texto através de leituras, entre as diferentes narrativas, a fim de se ter a construção de unidades de sentido e significados, para, posteriormente, proceder a elaboração de subtemas e temas, as quais foram interpretadas com base na hermenêutica e na articulação com o referencial teórico de suporte aos temas e subtemas de forma crítica ${ }^{16}$.

O tema elaborado com as narrativas dos entrevistados recebeu a denominação de compreensão do ritual de consumo e espaços do uso da substância, e seus subtemas foram respectivamente denomindados: subtema 1 - Inicio do uso; subtema 2 - forma de uso; subtema 3 - espaços para o consumo.

A pesquisa foi submetida ao Comitê de Ética em Pesquisa, da Universidade Estadual do Ceará, tendo sido aprovado para fins de sua realização, de acordo suas normas.

\section{Resultados e discussões}

Para entendermos a relação de consumo de uma substância psicoativa faz-se necessário a compreensão de como se constrói os rituais sobre o uso: aspectos relacionados ao início, as formas que se utilizam para consumir a droga, e todo o contexto social em que se dá o consumo dessa substância (local de uso, com quem se usa).

A temática aqui discutida refere-se ao ritual de consumo, no qual está inserido o crack. O uso de psicoativos não pode ser isolado do seu contexto social. Padrões de uso, quem usa o quê e como, estão sujeitos a diversos determinantes, tais como: a disponibilidade da droga, as tendências e as padronizações sociais. Além disso, outros elementos precisam ser levando em consideração: os valores, as regras e os rituais sobre o consumo, a estrutura de vida dos usuários, os quais estão sujeitos a variáveis e processos externos distintos, que vão desde fatores psicológicos pessoais e culturais até regulamentos oficiais e considerações mercadológicas ${ }^{10}$.

As narrativas dos sujeitos entrevistados discorrem sobre como se estrutura o ritual de consumo do crack, englobando aspectos importantes para a compreensão do fenômeno.

\section{Compreensão do ritual de consumo e espaços do uso da substãancia}

\section{Início do uso}

Com relação ao início do consumo de crack, os discursos apontam que o uso dessa droga procede do de outras substâncias psicoativas. Já é discutido na literatura que os usuários de crack geralmente são poliusuários, tanto que iniciaram antes com outras drogas, como mantém o uso de outras substâncias psicoativas concomitantes. O álcool e o tabaco são as drogas lícitas consumidas antes do início do uso do crack. A maconha é a substância ilícita usada pelos usuários antes de iniciarem o consumo do crack.

Destaca-se, em outros casos, o início do uso de cocaína em pó, havendo em seguida uma migração para a forma fumada de cocaína, geralmente em usuários que buscam a potencialização dos efeitos e da obtenção mais rápida, além do custo ser bem mais baixo. O fato dos usuários migrarem para o crack pode estar relacionado a quererem sentir novas sensações e a experimentarem um efeito mais intenso e diferente, como ilustram os discursos abaixo:

Quando eu tinha 12 anos eu comecei a fumar... a maconha não fazia mais o efeito que eu queria, eu passei pro crack por ser mais forte. [...] comecei a usar a cocaina, as mesmas pessoas lá da rua começaram a usar a cocaína, aí eu também fui na onda, aí eu comecei a cheirar também, aí logo depois veio o crack, foi o fim de força total. (Grupo I) 
Comecei meu uso com álcool, maconha e tudo. Usei maconha antes do crack... a minha história com as drogas começou com a maconha né, com o álcool, aí depois de alguns anos eu comecei a usar a cocaina e depois o crack, o crack veio por último. (Grupo I)

Cheguei em casa e senti cheiro de cola... só dormia se cheirasse cola... aí já entrou na maconha... aí começou a fumar na lata (Grupo II)

Deste modo, observa-se que o crack não costuma ser a primeira droga a ser usada, podendo haver a utilização de outras substâncias. A facilidade de ter acesso ao crack e de todas as outras drogas, sejam elas lícitas ou ilícitas, bem como o início precoce do consumo, tem-se mostrado um impulsionador do começo do uso. Desta forma, não são apenas os efeitos físico-químicos que impetram no individuo o desejo de usar ou de manter-se no uso, mas os aspectos sociais envolvidos nos contextos de uso.

Os aspectos subjetivos e sociais em relação ao início do uso do crack são pouco discutidos na literatura. A forma como uma sociedade se estrutura, como identifica e constrói seus valores são imprescindíveis para a discussão do consumo de substâncias psicoativas. Não é somente o aspecto relacionado às propriedades farmacológicas que impulsiona o consumo de uma determinada droga.

Os significados construídos socialmente, nos quais essa droga está inserida e como se dão suas representações na sociedade, também viabilizam o consumo dessa substância, dando sentido ao início desse uso. Um aspecto imprescindível para o início do consumo desta substância é detectado pelos usuários por ser uma nova droga, por ser moda, por ser novo.

$\mathrm{Na}$ sociedade na qual estamos inseridos, o consumo torna-se a prerrogativa máxima da organização social. A sociedade atual vive em prol do consumo, do que há de mais novo. A sociedade de consumo caracteriza-se pela elevação do nível de vida, abundância das mercadorias e dos serviços, culto aos objetos e aos lazeres, da moral hedonista e materialista. Uma sociedade centrada na expansão das necessidades é, antes de tudo, uma sociedade que se ordena através do consumo de massa sob a Lei da obsolescência, da sedução e da diversificação ${ }^{17}$. Ou seja, é uma sociedade que cultua o prazer imediato, em que os objetos tornam-se descartáveis, imperando a lógica da sedução em detrimento do autoritarismo, além de ser uma sociedade que se organiza em torno da diversidade de opções, porque a todo instante algo novo precisa ascender.
A sociedade pós-moderna, do capitalismo tardio, já não se submete a nenhum estado de necessidade; por isso, não há nenhuma razão que impeça a tendência da sociedade ao prazer, como no passado, nos século XIX e XX, se enalteceu a sociedade do trabalho. Na sociedade hedônica, a estética fala mais alto; é um retorno ao corpo, aos sentidos, aos prazeres que a sensualidade proporciona $^{18}$.

O mundo contemporâneo, mais do que o do passado da sociedade disciplinar, convoca para o prazer e o declínio dos deveres, desagarra-se dos medos, dos pecados e das obrigações que já não fazem sentido ${ }^{19}$. A busca por novas sensações ou a ideia de estar consumindo algo novo mobiliza as pessoas, reforçada pelas novidades constantes dos apelos comerciais. Aspecto bem ilustrado nos discursos dos usuários:

Ai apareceu o crack... aí como é uma coisa nova igual à moda... eu quis experimentar... A nova droga está aí... Já existia o crack há muito tempo em São Paulo, aí chegou aqui em Fortaleza, aí eu usei... eu sempre usei a cocaina, aí sempre tinha a curiosidade de experimentar o crack... ai o crack, ai eu gostei... aquela sensação muito boa (Grupo I).

Como se observa, o início do consumo tem relação com o modo como a sociedade se organiza. Um aspecto irônico parece se adequar bem à realidade do uso do crack. Nos tempos atuais, mesmo os excluídos do consumo são, a seu modo, hiperconsumistas, ou seja, todos aspiram se integrar a esse mundo, dos lazeres e das grifes famosas. Aqueles que não conseguem consumir os produtos que requerem grande aporte financeiro acabam optando pelo que está ao seu alcance, todos acabam se incorporando ao rol dos hiperconsumistas ${ }^{20}$. Destarte, destacamos que os consumidores de crack obedecem, em grande parte dos casos, a um padrão exagerado de uso, um consumo que tende a ser compulsivo e repetitivo, como se conforma nas narrativas:

teve um dia que eu virei a noite fumando cra$c k$... Aí você já quer outra, e quer outra. Enquanto você tiver dinheiro no bolso, você vai usando... Sensação de medo, angústia, o cara fica assombrado, assustado... fica com vontade de fumar mais... Insônia. Da vontade de dormir não. Só dá vontade de furmar mais, fumar mais (Grupo I)

Assim, o consumo do crack representa para este grupo de usuários a busca incessante pela novidade, máxima da sociedade de consumo atual. Há sempre um produto novo a ser consumido. A novidade faz parte da sociedade de consumo. O que é novo se mostra atraente e sedutor, assim como a necessidade de sentir novas 
sensações e de fazer parte de um grupo de consumidores.

O início do uso de crack pode se dar subsequente ao experimento de outras drogas. Os usuários entrevistados já consumiram outras substâncias psicoativas, passando a usar o crack no intuito de obter novas sensações, de experimentar prazeres diferentes e de sentir um efeito mais potente. Atrela-se à moda, ao fato de ser algo novo, uma droga nova, que todos estão usando por ter fácil acesso e pelo preço barato, já que a cocaína na sua forma aspirada tem um custo muito elevado. Interessante observar que o aumento do preço da cocaína tem influência direta no surgimento do crack e na disseminação do seu consumo, principalmente nas camadas sociais economicamente baixas, aspecto observado nos discursos:

Mas a gente sabe que não é só a substância, é a substância, o individuo e o contexto... Muitos faziam uso de álcool... É uma droga muito barata... Assim, é uma droga que hoje veio a complementar aquele vazio existencial, que cada um vai desenvolvendo ao longo da sua existência por conta das faltas de iniciativa própria e também do poder público, que não estende suas politicas públicas para pessoas que realmente se encontram na zona de vulnerabilidade socioeconômica e financeira [...] (Grupo II).

as drogas começou com a maconha né, com o álcool, aí depois de alguns anos eu comecei a usar a cocaina e depois o crack, o crack veio por último... Pra cocaina... Usava bastante mermo... Aí parei porque num tava fazendo efeito... eu cheirava e era mermo que nada... comecei no crack... quando eu tava fumando mais era nas bocada, né, que vende livremente, livremente eles vende pros aviciado (Grupo I).

O crack é uma alternativa de consumo da cocaína pelas populações mais carentes financeiramente. Diferentemente da simbologia de glamour assumida pela cocaína, o crack ocupou e ocupa um nicho mercadológico ligado às populações mais pobres e marginalizadas, utilizadas em ambientes inóspitos com um padrão compulsivo de consumo ${ }^{21}$.

Aspecto empiricamente observado nos discursos, é o fato do crack ser uma droga barata e de fácil acesso. A cocaína em pó, de boa qualidade, quando utilizada, tem um efeito mais prolongado no organismo humano, fazendo com que os usuários demorem mais tempo para repetir a dose.

O crack, portanto, torna-se o símbolo do consumo das camadas mais populares; a droga que se torna acessível às camadas mais desfavorecidas economicamente. Simboliza, ao mesmo tempo, a degradação, a mercadoria de péssima qualidade, originada do que sobrou de uma droga mais limpa e associada às camadas empresariais, símbolo de ostentação e poder, a cocaína requer maior poder aquisitivo, requer um refino, um trato refinado e diz respeito ao empreendedorismo, aa excitação intelectual. Por outro lado, o seu derivado mais sujo e nocivo fica acessível às camadas inferiores socialmente, aos miseráveis que não tem acesso à cocaína de boa qualidade, como representado nos discursos abaixo:

Em todo canto, em todo canto vende, em todo canto vende, a polícia derruba um, vem outro... Quanto mais você pode, mais você tem... Uns cinquenta reais... Dá pra comprar doze, dá pra comprar quinze... a pessoa por ser amigo já vende mais barato pra você... eu fumava mesclado e a partir dai eu comecei a usar frequentemente né... fácil acesso, preço barato [...] (Grupo I).

Assim é fácil acessar essas substâncias ilícitas. Mesmo sendo um mercado ilegal, as pessoas têm acesso de maneira precoce e fácil. Ou seja, não há uma efetividade das políticas públicas que visem coibir o uso delas. Além disso, o álcool, que tem seu comércio num mercado legal, possui fracas estratégias de controle quanto ao seu consumo. Portanto, estes fatores sociais são impulsionadores do inicio do uso do crack.

As consequências negativas do uso da cocaína fumada, para a saúde dos usuários, tem relação direta com as sanções sociais estabelecidas pelas políticas nacionais e internacionais relacionadas ao uso de drogas, já que o aparecimento delas tem relação com as ineficazes políticas impostas pelos governos nacionais e internacionais.

O estado de saúde dos indivíduos decorre das trajetórias do desenvolvimento pessoal no transcorrer de um período, confirmadas pela história de cada um e referida ao contexto social, econômico, político e tecnológico das sociedades nas quais tais trajetórias de desenvolveram. Os indivíduos não são independentes de seus grupos sociais na escolha dos hábitos de vida. Comportamentos socialmente desejáveis influenciam as escolhas aparentemente individuais, revelando a força dos hábitos coletivos ${ }^{22}$.

Dessa forma, fatores relacionados aos modelos sociais vigentes, políticas públicas ineficazes quanto à abordagem às drogas (licitas e ilícitas) têm articulação direta com o início do uso do crack, assim como o desenvolvimento de uma dependência dessa substância, discordando, desse modo, de teorias que atribuem ao potencial da 
substância de causar problemas de saúde e de viabilizar por si só a dependência em seus usuários.

\section{Formas de uso}

Concernente às formas de uso, o crack é utilizado de maneira fumada em latas, em cachimbos e em maricas, pode ser misturado com o tabaco, em cigarros conhecido como pitilho e com maconha, comumente chamado de mesclado.

Os discursos revelam que quem está fazendo uso do crack puro tem mais dificuldades de controlar o consumo do que quem, por exemplo, faz uso do mesclado, como representado nas narrativas:

Era mesclado, a pedra junto com a maconha e na lata... Fumo no cachimbo e na lata... Na lata é mais cruel, no mesclado a gente fuma uma vez e já se aqueta... Porque você fumando o crack puro ele é o efeito rápido. Se você fumar com maconha já leva assim... Fica mais demorado (Grupo I)

O que se percebe com esse tipo de uso que ele está tendo, se é na lata, que riscos pode trazer, em comparação com outros materiais, se ele fosse usar com outros materiais, como copinho d'agua, o cachimbo, o mesclado... Ficam queimado aqui no dedo por que quando a pessoa pega a lata ai ele queima o dedinho (Grupo II).

A forma de uso mais comum é na lata ou em cachimbos, sendo a substância absorvida de forma mais intensa. Considerando-se que a lata é o principal recipiente, o contato repetido com o alumínio aquecido lesa o tecido cutâneo, causando o aparecimento de bolhas e feridas na língua, nos lábios, rosto e dedos. Uma vez compartilhada o contato com o sangue de outros usuários, pode aumentar o risco de transmissão de doenças infectocontagiosas. Entre a população feminina, os agravos podem ser ainda maiores, já que usuárias, ao trocarem preferencialmente sexo oral e desprotegido por crack, possibilitam o contato de suas feridas com o sêmen do parceiro, o que lhes aumenta os riscos de contágio por doenças sexualmente transmissíveis, dentre elas o HIV. Somase a isto o fato de que o emprego das latas aumenta o nível sérico de alumínio, predispondo o usuário a possível intoxicação e danos neurológicos irreversíveis. Assim, considerados em conjunto, os dados anteriores aumentam os riscos de saúde que já estavam naturalmente associados ao uso do cachimbo convencional ${ }^{8}$.

O crack, por ser uma substância que ativa o sistema nervoso central, inibe a fome, fazendo com que os usuários não se alimentem e, consequentemente, baixem sua imunidade, deixandoos susceptíveis a doenças. O uso do crack puro, seja na lata, seja no cachimbo, tem seu efeito muito intenso e rápido, fazendo com que a pessoa queira repetir o consumo, levando a um padrão compulsivo de uso, o que traz mais efeitos nocivos, tais como dificuldades para se alimentar e para dormir, acarretando sérios problemas de saúde, como apreendido nas narrativas:

Eu emagreci mais... Por que quando você fuma em uma lata ela seca muito seu rosto... você emagrece, não consegue comer nada... Fumava assim, dez, quinze pedras... num conseguia dormir (Grupo I)

No entanto, observa-se que no uso do crack associado à maconha o efeito desejado demora a passar e o usuário não tem vontade de repetir a dose. Além disso, o efeito narcótico da maconha faz com que os usuários de crack tenham menos fissura para tornar a usá-lo, sendo esta uma possível estratégia de redução de danos.

Estudos apontam que a maconha é utilizada como paliativo aos efeitos negativos de crack. Sua adoção poderia ser uma importante estratégia para a redução dos danos associados ao uso crônico de crack, pois diminui a fissura e os demais sintomas ligados à síndrome de abstinência, o que possibilitaria, em longo prazo, a reintegração sociolaboral do usuário ${ }^{8,23}$.

A maconha, embora não interfira sobre a intensidade dos efeitos positivos, parece prolongar sua duração, seja administrada simultaneamente (como mesclado) ou após crack (na forma de baseado). O uso combinado com o cloridrato de cocaína (via aspirada) aumenta a intensidade e a duração dos efeitos positivos, além de atuar como paliativo dos efeitos negativos. O emprego da maconha por usuários de crack é tão intenso, que chegaria a ultrapassar em frequência o realizado pelos exclusivos de cloridrato de cocaína ${ }^{24}$.

No entanto, o uso combinado da maconha com o crack tem sido criticado pelo fato de ser a maconha mais uma droga utilizada e por isso trazer mais prejuízos e danos, havendo uma falsa crença de que esta forma de emprego levaria a padrões mais leves de consumo. De acordo com esta ideia, os usuários do mesclado acabariam se tornando compulsivos da mesma maneira que aqueles de crack na forma de pedra ${ }^{25}$.

Negar a possibilidade de haver outras formas de consumo do crack é negar todo o processo social e cultural envolvido nas questões do uso. As adequações dos usuários são estratégias construídas a partir das trocas sociais que ocorrem no momento do uso. Este não se dá de maneira isolada, nem independente dos efeitos da substância utilizada, ou dos aspectos idiossin- 
crático dos usuários, tampouco das construções coletivas, fruto da dinâmica social estabelecida entre o grupo, o que pode viabilizar formas de uso menos danosas.

Conhecer os determinantes mais complexos do comportamento humano, além das condições materiais de vida dos grupos sociais, é necessário para que as práticas de promoção da saúde e de prevenção possam ser efetivas ${ }^{22}$.

No atendimento ao usuário não se pode apartá-lo das drogas. É importante construir junto o desenvolvimento do sentido desse uso, assim como significar o domínio da sua responsabilidade na prática com as drogas, caso não seja desejo do usuário privar-se delas. É crucial compreender a interpretação que os sujeitos dão à experiência com as drogas, de seu estado, da motivação que os impele ao consumo repetido de determinada substância, dos sentidos e razões pelas quais as consideram importante. As especificidades subjetivas e individuais do uso de qualquer substância são condicionadas e estruturadas por forças culturais e históricas ${ }^{26}$.

O campo das ações e opiniões individuais é sempre resultado de injunções sociais, e todas as particularidades se inserem num mundo de determinações sociais, inclusive no que se refere às atitudes e juízos pessoais. As margens de adequação, mesmo as mais íntimas, obedecem em última instância a parâmetros coletivos. A individualidade psíquica é constituída baseada num processo social e histórico ${ }^{27}$.

Daí não desconsiderarmos os aspectos constitutivos do processo de relação entre o usuário, a substância e o seu contexto sociocultural. Assim, é preciso identificar os espaços sociais em que este consumo se dá, para se identificar possibilidades de intervenção condizentes com a realidade que se apresenta.

\section{Espaços para o consumo}

No que diz respeito aos lugares de uso, observa-se que o crack é utilizado nos mais diversos espaços. Pode acontecer de forma isolada ou de forma coletiva. Na casa de amigos, parentes ou até mesmo na própria. Nos discursos podemos perceber que há vários espaços onde este uso pode acontecer, diferentemente do que vem sendo demonstrado na mídia; que os locais de uso estão concentrados nas cracolândias, lugares específicos, geralmente na área central das grandes cidades, o que se pode observar nas narrativas:

Quintal, casa baldia, quintal de casa, nos matos, tinha vários cantos, tinha canto não, onde desse eu fumava... De primeiro eu saia de casa aí compro e ficava fumando dentro de casa mesmo, eu num tenho aquele hábito de fica no meio da rua, ficar na esquina, passar a noite no meu do mundo, essa coisa eu ainda num tenho não e nem quero ter... Sempre dentro de casa né? No meu apartamento (Grupo I)

O fator financeiro também é preponderante para se definir os locais de uso. Usuários com melhor poder aquisitivo fazem uso em locais mais protegidos, evitando o contato com ambientes sujos e inóspitos, descritos muitas vezes nos estudos $^{25}$. A preferência por um uso mais isolado, dentro da própria casa, é relatada pelos usuários como uma forma de evitar o risco de agressões, violência e pelo estigma que sofrem. Aspecto também detectado nas narrativas dos trabalhadores de saúde:

Em alguns lugares onde o uso é feito há mortes, muitas brigas e tudo por conta disso, esse clima de medo é muito terrível, o crack é a droga do medo (Grupo II).

No seu surgimento, o consumo de crack estava restrito às populações desfavorecidas economicamente e se dava geralmente em locais sujos. No entanto, tem-se observado que o consumo permeia todas as classes sociais, e não somente grupos em situação de vulnerabilidade. Porém, os danos sociais e de saúde acabam atingindo de forma mais intensa os grupos que apresentam maior vulnerabilidade.

O ambiente em que se consome o crack é pautado pela desconfiança; os usuários que antes conseguiam compartilhar as experiências positivas do uso começam a se desorganizar socialmente, ou tendo que se organizar de outra forma. Uma forma que não se pode mais confiar em ninguém, em que ninguém confia mais em você. O contexto social de uso do crack, embora haja compartilhamento entre os usuários, também apresenta desconfianças e intrigas. Isto extrapola para os demais espaços de convívio social do usuário, como trabalho, família etc.

Determinados grupos sociais apresentam maior vulnerabilidade quando utilizam o crack, demonstrando mais uma vez que não se trata apenas do efeito da substância no organismo humano que promove os danos sociais e à saúde de seus usuários, mas todo o contexto de uso e as características sociais dos grupos que o utilizam. Fatores como: gênero - usuárias do sexo feminino são mais vulneráveis a abuso sexual e agravos de ordem física; faixa-etária - usuários jovens e adultos jovens usam crack mais frequentemente associado a processos disruptivos em relação à sua vida social; o vínculo com institui- 
ções como família, escola e inserção no trabalho formal ou informal, ou seja, usuários de crack que mantêm, minimamente, uma rede de apoio familiar e social e vinculações formais no mercado de trabalho têm mais recursos de acesso ao cuidado, bem como maior alcance a fatores de proteção. Observa-se que a baixa escolaridade implica, entre outros aspectos, menor inserção no mercado formal, menor disponibilidade financeira e, consequentemente, maior vulnerabilidade. As comorbidades psiquiátricas, como transtornos de humor ou quadros psicóticos, implicam frequentemente em pior prognóstico em avaliações prospectivas. Os delitos, situações de conflitos com a lei, especialmente associação com tráfico, implicam uma maior exposição à violência e, portanto, maior vulnerabilidade ${ }^{28}$.

Outra característica trazida nos discursos é o fato dos usuários geralmente elegerem estes lugares de uso e permanecerem sem se comunicar com mais ninguém. Mantêm-se isolados ou em grupo fazendo somente uso da substância, ou seja, os usuários se "internam” em algum espaço para ficar só usando a droga.

O consumo do crack tem acontecido em diversos espaços, não se verificando um específico e comum para que ele ocorra. Pode se dar em terrenos baldios, mas também dentro da própria casa do usuário. Porém, há algo que se destaca quanto à cena de uso: o usuário de crack realiza o consumo de forma compulsiva, sem se ausentar do espaço para realizar as demais atividades da sua vida, como destacado nos discurso a seguir:

Teve uma vez que eu me internei na favela usando... Tinha um outro canto pra fumar, uma casa abandonada... só saía de lá quando fumava tudo (Grupo I)

ele passa vários dias, eles chamam de estar internado, ou seja, usando direto dentro da favela e outros lugares. Eles não saem para nada, nem para tomar banho, se alimentar, só consumindo droga (Grupo II)

O espaço acaba sendo uma referência onde o usuário permanece boa parte do seu cotidiano experimentando os efeitos da substância. Diante dessa constatação, faz-se necessário que as intervenções de saúde também aconteçam nesses lugares, mediante vinculação com espaços sociais de consumo dos usuários.

Usuários de crack com maior comprometimento social parecem não chegar às redes de saúde, o que remete à necessidade dos municípios e dos serviços implementarem estratégias de facilitação do acesso, com maior envolvimento de agentes comunitários de saúde, com os Programas de Redução de Danos (PRD) ou com os Consultórios de Rua, ou outras ações de aproximação entre comunidade e serviços ${ }^{29}$.

\section{Considerações finais}

Os resultados do estudo revelam como os aspectos relacionados ao contexto social do consumo do crack têm estreita relação com os danos à saúde do usuário. O início do consumo tem associação com a experimentação de outras substâncias psicoativas, com os modelos sociais de consumo da sociedade e com o baixo preço da droga. O acesso precoce às drogas lícitas, facilitado por políticas públicas ineficazes, os valores sociais que estimulam o excesso de consumo, o fácil acesso e o baixo preço do crack, além da péssima qualidade da droga, reforçam o padrão compulsivo do uso com consequências diretas à saúde física, psíquica e social dos usuários.

Além disso, as formas de uso do crack, mais do que o efeito da substância, parecem piorar os problemas de saúde. A utilização de latas para o consumo do crack, de forma pura, tem levado os usuários a um padrão de uso compulsivo. Já o uso concomitante do crack com a maconha mesclado - tem promovido um padrão menos compulsivo e, por conseguinte, menos danoso.

Por fim, faz-se necessário que os estudos absorvam elementos do contexto social e cultural das cenas de uso, no intuito de obter subsídios para a compreensão do fenômeno, viabilizando intervenções mais condizentes pelos trabalhadores de saúde, desenvolvendo estratégias através das próprias ferramentas de controle que os usuários utilizam para se protegerem das consequências adversas do consumo do crack.

\section{Colaboradores}

MSB Jorge, PHD Quinderé, S Yasui e RA Albuquerque participaram igualmente de todas as etapas de elaboração do artigo.

\section{Agradecimentos}

Ao $\mathrm{CNPq}$ pelo financiamento do projeto. 


\section{Referências}

1. Perrenoud LO, Ribeiro M. Histórico do consumo de crack no Brasil e no mundo. In: Laranjeira $\mathrm{R}$, Ribeiro M, organizadores. O tratamento do usuário do crack. Porto Alegre: Artemed; 2012. p. 33-38.

2. Nappo SA, Galduróz JCF, Noto AR. Crack use in São Paulo. Subst Use Misuse 1996; 31(5):565-579.

3. Carlini AE, Galduróz JCF, Noto AR, Nappo SA. I Levantamento domiciliar sobre o uso de drogas psicotrópicas no Brasil: estudo envolvendo as 107 maiores cidades do país: 2001. São Paulo: Centro Brasileiro de Informações Sobre Drogas Psicotrópicas (Cebrid), Universidade Federal de São Paulo (Unifesp); 2002.

4. Carlini AE, Galduróz JCF, Noto AR, Nappo SA. II levantamento domiciliar sobre o uso de drogas psicotrópicas no Brasil: estudo envolvendo as 108 maiores cidades do país: 2005. São Paulo: Centro Brasileiro de Informações Sobre Drogas Psicotrópicas (Cebrid), Universidade Federal de São Paulo (Unifesp); 2005.

5. Laranjeira R, organizador. II Levantamento Nacional de álcool e drogas: o uso de cocaína e crack no Brasil. São Paulo: Unifesp, Inpad, Uniad; 2012.

6. Nappo SA, Galduróz JCF, Raymundo M, Carlini EA. Changes in cocaine use as viewed by key informants: a qualitative study carried out in 1994 and 1999 in São Paulo, Brazil. J Psychoactive Drugs 1999; 33(3):241-253.

7. Sanchez ZVDM, Nappo SA. Sequência de drogas consumidas por usuários de crack e fatores interferentes. Rev Saude Publica 2002; 36(4):420-430.

8. Oliveira LG, Nappo SA. Crack na cidade de São Paulo: acessibilidade, estratégias de mercado e formas de uso. Rev Psiq Clín 2008; 35(6):212-218.

9. Macrae E, Vidal SS. A Resolução 196/96 e a imposição do modelo biomédico na pesquisa social Dilemas éticos e metodológicos do antropólogo pesquisando o uso de substâncias psicoativas. Rev. Antropol. 2006; 49(2):645-666.

10. Zinberg N. The Social Setting as a Control Mechanism in Intoxicant Use. In: Lettieri DJ, Mayers M, Pearson, HW, editors. Theories on drug Abuse, NIDA Research Monograph 30. Rockville: NIDA; 1980. p. 236-244.

11. Macrae E. Antropologia: aspectos sociais, culturais e ritualísticos. In: Seibel SD, organizador. Dependência de Drogas. São Paulo: Atheneu; 2010. p. $27-$ 37.

12. Romaní O. Etnografía y drogas: discursos y prácticas. Rev Nueva Antropologia 1997; XVI(53-52):3966.

13. Grund, JPC. Drug Use as a Social Ritual - Functionality, Symbolism and Determinants of Self-Regulation. Roterdã: Institut voor Vershavingsonderzock (IVO) Erasmus Universiteit; 1993.

14. Ricouer P. Do texto à ação: ensaios de hermenêutica II. Portugal: RÉS - Editora; 1991.

15. Geanellos R. Exploring Ricoeur's hermeneutic theory of interpretation as a method of analysing research texts. Nurs Inq 2000; 7(2):112-119.

16. Trivinos ANS. Introdução à pesquisa em ciências sociais: a pesquisa qualitativa em educação. São Paulo: Atlas; 1992.
17. Lipovetsky G. O império do efêmero: a moda e seu destino nas sociedades modernas. São Paulo: Compahia das letras; 2009.

18. Nery Filho A, Macrae E, Tavares LA, Rêgo M, organizadores. Toxicomanias: incidências clínicas e socioantropológicas. Salvador: Edufba, Cetad; 2009.

19. Espinheira G. A universalidade dos usos de drogas: o lugar das drogas na sociedade pós-moderna. (Conferência: O homem e sua relação com as drogas: história, valores e políticas - 27 de abril de 2004 Local: Quality Suítes, salão Itamarati). In: $1^{\circ}$. Encontro Nacional de CAPS AD - Centros de atenção psicossocial álcool e outras drogas: Drogas, saúde pública e democracia. Reduzindo danos, ampliando direitos; 2004; Santo André, São Paulo.

20. Lipovetsky G. A sociedade da decepção. Barueri: Manolo; 2007.

21. Ferreira Filho OF, Turchi MD, Laranjeira R, Castelo A. Perfil sociodemográfico e de padrões de uso entre dependentes de cocaína hospitalizados. Rev Saude Publica 2003; 37(6):751-759.

22. Barata RB. Desigualdades sociais e saúde. In: Campos GWS, Minayo MCS, Akerman M, Drumond Júnior M, Carvalho YM, organizadores. Tratado de saúde coletiva. São Paulo, Rio de Janeiro: Hucitet, Fiocruz; 2009. p. 457-486.

23. Labigalini JRE, Rodrigues LR, Silveira DXJ. Therapeutic use of cannabis by crack addicts in Brazil. $J$ Psychoactive Drugs 1999; 31(4):451-455.

24. Gossop M, Manning V, Ridge G. Concurrent use of alcohol and cocaine: differences in patterns of use and problems among users of crack cocaine and cocaine powder. Alcohol Alcohol 2006; 41(2):121-125.

25. Ribeiro M, Nappo SA, Sanchez ZVDM. Aspectos socioculturais do consumo de crack. In: Laranjeira R, Ribeiro M, organizadores. O tratamento do usuário do crack. Porto Alegre: Artemed; 2012. p. 50-56.

26. Labate BC, Goulart SL, Fiore M, Macrae E, Carneiro $\mathrm{H}$, organizadores. Drogas e Cultura: novas perspectivas. Salvador: Edufba; 2008.

27. Carneiro H. Autonomia e heteronomia nos estados alterados de consciência. In: Labate BC, Goulart SL, Fiore M, Macrae E, Carneiro H, organizadores. Drogas e cultura: novas perspectivas. Salvador: Edufba; 2008. p. 65-90.

28. Brasil. Ministério da Saúde (MS). Abordagens Terapêuticas aos usuários de Cocaina/Crack no Sistema Único de Saúde. Brasília-DF; 2010. Brasil. Ministério da Saúde (MS). Departamento de Atenção Básica. Atenção Básica e Saúde da Família [site na Internet]. 2011 [acessado 2011 set 22]. Disponível em: http://www.dab.saude.gov.br/atencaobasica.php

29. Horta RL, Horta BL, Rosset AP, Horta CL. Perfil dos usuários de crack que buscam atendimento em Centros de Atenção Psicossocial. Cad Saude Publica 2011; 27(11):2263-2270.

Artigo apresentado em 25/03/2013

Aprovado em 14/05/2013

Versão final apresentada em 27/05/2013 